\title{
A Novel Improved RP-HPLC Method for the Estimation of Dothiepin Hydrochloride in Bulk and Pharmaceutical Dosage Form
}

\author{
Vijaya lakshmi.M*, M.Srinavyatha, Lakshmi Prasanna.M, Buchi N.Nalluri \\ Department of Pharmaceutical Analysis, K.V.S.R.Siddhartha College of Pharmaceutical Sciences, \\ Vijayawada-520010, A.P, India.
}

\begin{abstract}
A Simple and precise reverse phase high performance liquid chromatography(RP-HPLC)method was developed and validated for the estimation of Dothiepin hydrochloride in bulk and pharmaceutical dosage form. The optimization is carried out on an Inertsil ODS $3(250 \times 4.6 \mathrm{~mm}$, $5 \mu$ particle size) long column with a mobile phase of Formic acid(0.02\%): Acetonitrile in the ratio of $72: 28 \mathrm{v} / \mathrm{v}$ at a flow rate of $1 \mathrm{ml} / \mathrm{min}$ with UV detection at $230 \mathrm{~nm}$ using LC solution software. The Linearity of Dothiepin hydrochloride was observed in the concentration range of $2-10 \mu \mathrm{g} / \mathrm{ml}\left(R^{2}=0.999\right)$. The proposed method has shown consistent recovery of Dothiepin 99.41-100.85\% with the labeled amount in the pharmaceutical formulation. The proposed method was successfully applied for the quantification of active drug in tablet dosage form.
\end{abstract}

Keywords: Dothiepin hydrochloride, RP-HPLC, ICH guidelines and method validation.

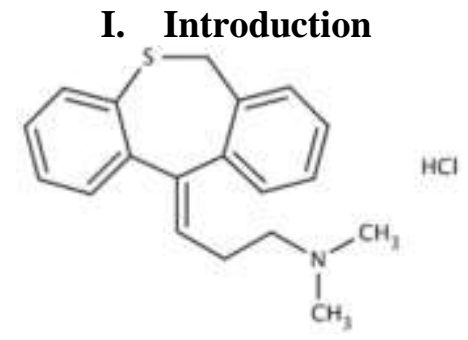

Figure 1: Structure of Dothiepin hydrochloride.

Dothiepin hydrochloride chemical name is 3-dibenzo [b, e] thiepin-11(6H)-ylidene-N,N-dimethyl-1propanamine hydrochloride ${ }^{[1]}$. Dothiepin is white to faintly yellow, crystalline powder, odourless or almost odourless ${ }^{[2]}$. Dothiepin is a tri-cyclic antidepressant with similar actions of amitriptylline. It is freely soluble in water, alcohol and in dichloromethane. Dothiepin (Dosulepin) hydrochloride is readily absorbed from GIT and extensively demethylated by first pass metabolism in the liver to its primary active metabolite desmethyldothiepin. It is excreted in urine or in faeces ${ }^{[3]}$.

Literature survey reveals that Liquid chromatography-Mass spectroscopy(LC-MS ${ }^{[4]}$, Electrometric ${ }^{[5-6],}$ Conductometric $^{[7]}$, Stability indicating ${ }^{[8-9]}$, UV Spectroscopic ${ }^{[10-11]}$, RP-HPLC methods ${ }^{[12-16]}$ were reported for the estimation of Dothiepin hydrochloride in bulk, combination dosage forms and in plasma samples. Therefore attempts were made to develop simple RP-HPLC method which is LC-MS compatible for the estimation of Dothiepin hydrochloride in bulk and its dosage form and validated as per ICH guidelines ${ }^{[17-18]}$.The chemical structure of Dothiepin hydrochloride is shown in Fig 1.

\section{Chemicals and reagents}

\section{Experimental details}

Dothiepin hydrochloride was obtained as a gift sample from Life line formulations Pvt. limited, Vijayawada, India. All the other chemicals needed for the experiment were of HPLC grade and were purchased from MERCK chemicals. The Chemicals required for the experiment are formic acid, ammonium acetate, methanol and acetonitrile.

\section{Instrument and chromatographic conditions}

Chromatography was carried out on HPLC Shimadzu prominence technology. The chromatographic system was equipped with LC-10 ATVP series binary pump systems, SIL-20 AHT Auto sampler, SPD-10AVP UV-VIS detector and data acquisition was carried out using LC solution software. The chromatographic separation was performed using Inertsil ODS $3(250 \times 4.6 \mathrm{MM}, 5 \mu$ particle size $)$ long column. 
The chromatographic seperation was achieved at an ambient temperature using a mobile phase consisting of $0.02 \%$ formic acid and acetonitrile in the ratio of $72: 28 \mathrm{v} / \mathrm{v}$ which is pumped at a flow rate of $1 \mathrm{ml} / \mathrm{min}$.The overall run time was $7 \mathrm{~min}$ and $10 \mu \mathrm{l}$ of sample was injected into HPLC System. The eluent was monitored at a wavelength of $230 \mathrm{~nm}$ using UV-VIS detector.

\section{Preparation of mobile phase}

A $0.02 \%$ Formic acid solution was prepared by dissolving $200 \mu \mathrm{l}$ of formic acid in $1000 \mathrm{ml}$ of HPLC grade water. The solution was filtered through $0.45 \mu \mathrm{m}$ nylon membrane filter to remove all fine particles and sonicated for $30 \mathrm{sec}$ to remove any dissolved gases.

\section{Preparation of standard stock solution}

Weigh accurately about $10 \mathrm{mg}$ of dothiepin hydrochloride in a clean, dry $10 \mathrm{ml}$ volumetric flask and few $\mathrm{ml}$ of methanol was added to dissolve completely and then the volume is made up to the mark with methanol to obtain a concentration of $1 \mathrm{mg} / \mathrm{ml}$. Further dilutions were carried out with $0.02 \%$ formic acid as a diluent to get a series of concentrations $2-10 \mu \mathrm{g} / \mathrm{ml}$.

\section{Method validation}

The developed method for the estimation of dothiepin hydrochloride was validated as per ICH guidelines $^{[9-10]}$ for the parameters like linearity, system suitability, specificity, accuracy, precision, robustness, limit of detection(LOD), limit of quantification(LOQ).

\section{Linearity}

Aliquots of 40,80,120,160, 200 $\mu 1$ of solution was pipetted out from standard stock solution and make up the volume up to $1 \mathrm{ml}$ individually with $0.02 \%$ Formic acid to get a concentration of $2,4,6,8,10 \mu \mathrm{g} / \mathrm{ml}$ of Dothiepin hydrochloride. The calibration curve is constructed for the dothiepin hydrochloride to check for linearity over the concentration range of $2-10 \mu \mathrm{g} / \mathrm{ml}$. The regression and correlation coefficients were calculated. Acceptance criteria: Correlation coefficient not less than 0.999

\section{Accuracy}

Accuracy was assessed by determining the recovery of the method at three different concentrations (corresponding to $80,100,120 \%$ of the test solutions) by the addition of the known amount of standard to placebo preparation. At each level three sets were prepared and injected in triplicate.

\section{Precision}

The precision is carried out by injecting the standard preparation concentration of $6 \mu \mathrm{g} / \mathrm{ml}$ concentration of Dothiepin hydrochloride for six times and the \%RSD for six replicate injections was calculated. Acceptance criteria: The \% RSD for the peak areas of standard injections should not more than $2 \%$.

\section{Robustness}

To evaluate the robustness of a LC method a few chromatographic parameters are deliberately varied. The parameters include flow rate, percentage of organic phase in mobile phase, wavelength. Only one factor at a time was changed to observe the effect. Thus three injections of standard solution were performed under the change of three chromatographic parameters.

\section{System suitability}

The suitability of the proposed method should be tested before each stage of the validation. Five replicate injections of standard solution $(6 \mu \mathrm{g} / \mathrm{ml})$ was injected with increased volume of (10-50 $\mu 1)$ into HPLC system and the parameters like number of theoretical plates, tailing factor and statistically relative standard deviation was calculated.

\section{Limit of detection(LOD) and limit of quantification (LOQ)}

The LOD is the smallest concentration of the analyte that gives a measurable response and LOQ is the smallest concentration of the analyte which can give the responses that can be quantified accurately. The LOD and LOQ values were determined based on the signal to noise ratios and based on the analytical responses of 10 and 3 times the background noise respectively.

$\mathrm{LOD}=3.3 \times \sigma / \mathrm{S}$

$\mathrm{LOQ}=10 \times \sigma / \mathrm{S}$

Where $\sigma=$ Standard deviation and $\mathrm{s}=$ slope of the equation. 


\section{Stability of solution}

The stability of the solution was assessed both for test and standard preparation. The solutions were prepared and stored at $5^{\circ} \mathrm{c}$ and at ambient temperature without protection of light and tested after $24 \mathrm{hrs}$. The responses were determined for the aged sample and was compared with freshly prepared sample.

\section{Specificity}

The specificity of the RP-HPLCmethod was evaluated by injecting the blank and standard preparations into the HPLC system. The effect of excipients and other additives in the dosage form of dothiepin hydrochloride under the optimum conditions was evaluated and no interferences were observed.

\section{Analysis of marketed formulation}

Twenty tablets were weighed accurately and grounded into fine powder and the powder blend equivalent to $10 \mathrm{mg}$ of dothiepin hydrochloride was transferred into a clean and dry $10 \mathrm{ml}$ volumetric flask. About $5 \mathrm{ml}$ of methanol was added and the solution was sonicated for $3 \mathrm{~min}$ to extract the Dothiepin and the volume was made upto the mark with methanol. The solution was filtered through $0.45 \mu \mathrm{m}$ nylon membrane filter and the filtrate was appropriately diluted with $0.02 \%$ formic acid to make the concentration of $6 \mu \mathrm{g} / \mathrm{ml}$ and the results were tabulated.

\section{Results and discussion}

To develop an effective LC-MS compatible method for the analysis of the dothiepin, various LC-MS compatible mobile phases such as ammonium acetate, ammonium formate was tried. The method is optimized with satisfactory separation and good peak symmetry. The mobile phase composition containing a mixture of Formic acid (0.02\%): ACN was used in the ratio of $72: 28 \mathrm{v} / \mathrm{v}$ at a flow rate of $1 \mathrm{ml} / \mathrm{min}$ with a retention time of $4.38 \mathrm{~min}$.

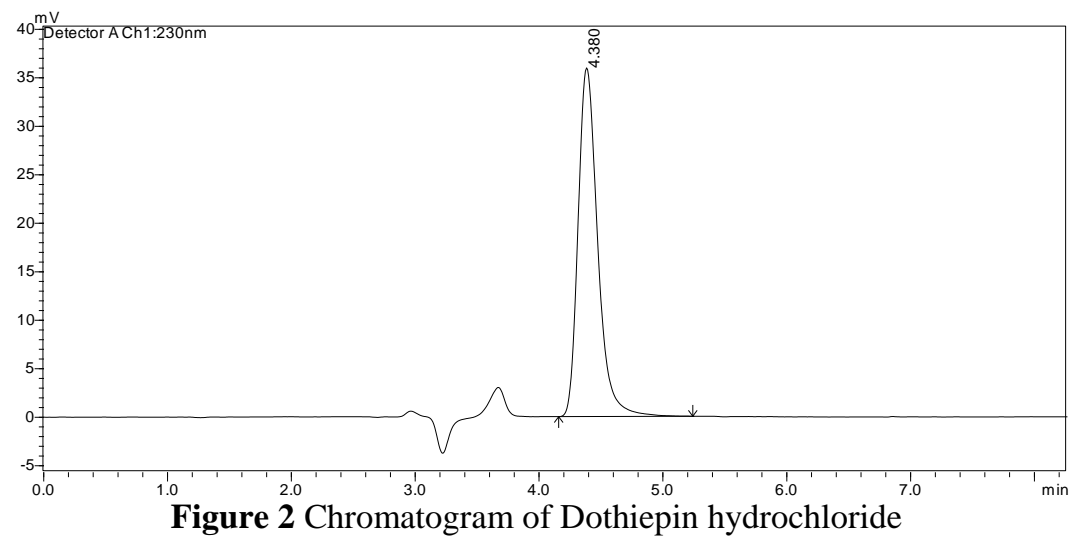

Validation of the proposed RP-HPLC method was performed as per ICH guidelinesQ2 (R1). The linearity was established in the concentration range of $2-10 \mu \mathrm{g} / \mathrm{ml}$ with a correlation coefficient of 0.999 . The $\%$ accuracy was found to be 98.3-103.42 which indicates the accuracy of the proposed method. The \%RSD value is 0.00051 reveals that the method is precise. The system suitability was carried out by injecting freshly prepared sample solutions and the parameters like \%RSD was with in the limit $(<2 \%)$.

Robustness of the method was studied by changing the chromatographic parameters like flow rate, mobile phase composition etc. Specificity was carried out by injecting blank, placebo and sample but no interferences are observed around the Dothiepin peak. The LOD and LOQ values were found to be 0.0592 and $0.1794 \mu \mathrm{g} / \mathrm{ml}$ respectively. From the above data we can conclude that the proposed method was found to be simple, precise, accurate, specific and robust, hence it is used for the Quality control analysis of Dothiepin in bulk and dosage form.

Table 1 :Optimised chromatographic parametres of HPLC method

\begin{tabular}{|c|c|}
\hline Equipment & Shimadzu's prominence HPLC system \\
\hline Column & Inertsil ODS 3 long $(250 \times 4.6 \mathrm{~mm}, 5 \mu \mathrm{m}$ particle size $)$ \\
\hline Mobile phase & Formic acid $(0.02 \%): \mathrm{ACN}(72: 28 \mathrm{~V} / \mathrm{V})$ \\
\hline Injection volume & $10 \mu \mathrm{L}$ \\
\hline Flow rate & $1 \mathrm{ml} / \mathrm{min}$ \\
\hline Column temperature & Ambient \\
\hline Wavelength & $230 \mathrm{~nm}$ \\
\hline Concentration of standard solution & $10 \mu \mathrm{g} / \mathrm{ml}$ \\
\hline
\end{tabular}




\section{Robustness}

Robustness was evaluated by making very slight changes in the chromatographic parameters. Different parameters like retention time, theoretical plates and tailing factor were recorded. The results were tabulated in table 2, 3and 4 .

Table 2: Robustness data related to flow rate change

\begin{tabular}{|l|l|l|l|l|}
\hline S.no. & Flow rate (ml/min) & Retention time (min) & Plate count & Tailing factor \\
\hline 1. & 0.8 & 5.781 & 4673.447 & 1.472 \\
\hline 2. & 1 & 4.66 & 3886.573 & 1.478 \\
\hline 3. & 1.2 & 4.076 & 4387.118 & 1.410 \\
\hline
\end{tabular}

Table 3: Robustness data related to mobile phase ratio change

\begin{tabular}{|l|l|l|l|l|}
\hline S.no & Mobile phase ratio(v/v) & Retention time (min) & Plate count & Tailing factor \\
\hline 1. & $74: 26$ & 6.425 & 4387.118 & 1.443 \\
\hline 2. & $72: 28$ & 4.66 & 4153.245 & 1.478 \\
\hline 3. & $70: 30$ & 3.689 & 8826.306 & 0.697 \\
\hline
\end{tabular}

Table 4: Robustness data related to wavelength change

\begin{tabular}{|l|l|l|l|l|}
\hline S.no. & Wavelength(nm) & Retention time & Plate count & Tailing factor \\
\hline 1. & 229 & 4.32 & 4150.258 & 1.458 \\
\hline 2. & 230 & 4.66 & 4153.245 & 1.478 \\
\hline 3. & 231 & 4.40 & 4152.248 & 1.452 \\
\hline
\end{tabular}

\section{Linearity}

Linearity was obeyed in the concentration range of $2-10 \mu \mathrm{g} / \mathrm{ml}$ with a correlation coefficient of 0.999 . The calibration curve was shown in figure 3 and the results were tabulated in table 5.

Table 5: Linearity of Dothiepin hydrochloride

\begin{tabular}{|l|l|l|}
\hline S.no & Concentration $\boldsymbol{\mu g} / \mathbf{m l}$ & Peak area \\
\hline 1. & 2 & 79136 \\
\hline 2. & 4 & 155469 \\
\hline 3. & 6 & 230451 \\
\hline 4. & 8 & 308942 \\
\hline 5. & 10 & 375680 \\
\hline Regression equation Y=37328x+5967.3 \\
\hline Regression coefficient $\mathbf{R}^{\mathbf{2}}=\mathbf{0 . 9 9 9}$ \\
\hline
\end{tabular}

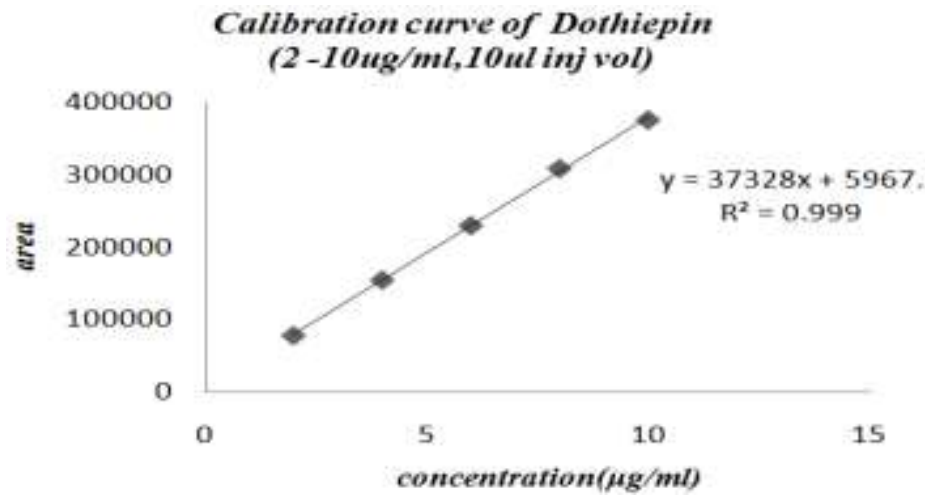

Figure 3 : Calibration curve of Dothiepin hydrochloride

\section{Accuracy}

Accuracy of the proposed method was carried out by carrying out the recovery studies by standard addition method. The \% recovery was found to be 99.41-100.85 and the results were tabulated in table 6 .

Table 6 Accuracy data

\begin{tabular}{|l|l|l|l|l|l|}
\hline S.no & Level of recovery & $\begin{array}{l}\text { Amount } \\
\text { present }(\boldsymbol{\mu g} / \mathbf{m l})\end{array}$ & $\begin{array}{l}\text { Amount } \\
\text { added }(\boldsymbol{\mu g} / \mathbf{m l})\end{array}$ & $\begin{array}{l}\text { Amount } \\
\text { recovered( } \boldsymbol{\mu g} / \mathbf{m l})\end{array}$ & \%ecovery+S.D \\
\hline 1. & 80 & 6 & 4.8 & 5.95 & $99.41+0.197$ \\
\hline 2. & 100 & 6 & 6 & 5.98 & $99.73+0.443$ \\
\hline 3. & 120 & 6 & 7.2 & 6.06 & $100.85+0.215$ \\
\hline
\end{tabular}




\section{Precision}

Precision was carried out by injecting repeatedly the standard $6 \mu \mathrm{g} / \mathrm{ml}$ solution for 6 times and the $\%$ RSD was within the limits $<2$ for peak areas and less than 1 for retention time. The data was evaluated and theresults were tabulated in table 7.

Table 7 Precision data

\begin{tabular}{|l|l|l|l|}
\hline S.no & Sample & Retention time(min) & Area \\
\hline 1. & Injection 1 & 4.66 & 230451 \\
\hline 2. & Injection 2 & 4.676 & 230450 \\
\hline 3. & Injection 3 & 4.688 & 230452 \\
\hline 4. & Injection 4 & 4.687 & 230453 \\
\hline 5. & Injection 5 & 4.691 & 230451 \\
\hline 6. & Injection 6 & 4.685 & 230450 \\
\hline \multicolumn{2}{|l|}{ Average } & 4.681 & 230451 \\
\hline \multicolumn{2}{|c|}{ Standard deviation } & 0.01155 & 1.6905 \\
\hline \multicolumn{2}{|c|}{ RSD } & 0.2467 & 0.00051 \\
\hline
\end{tabular}

\section{Limit of detection (LOD) and Limit of Quantification (LOQ)}

The LOD and LOQ values were calculated based on the values of slopes and intercepts of the calibration curve. The Limit of detection and the Limit of quantification values for the estimation of Dothiepin hydrochloride was found to be 0.0592 and $0.1794 \mu \mathrm{g} / \mathrm{ml}$ respectively.

\section{Stability in sample solution}

There were no interferences in the chromatogram of Dothiepin hydrochloride reveals the stability of drug in the sample solution.

\section{System suitability}

System suitability was performed by injecting the sample solution at increasing injection volume into the HPLC system. The parameters like retention time, peak area, theoretical plates, tailing factor was evaluated. The values are summarized in Table 8.

Table 8: System suitability data

\begin{tabular}{|c|c|c|c|c|}
\hline S.no. & Injection volume $(\mu \mathrm{l})$ & Retention time (min) & Tailing factor & Theoritical plates(N) \\
\hline 1. & 10 & 4.66 & 1.478 & 230451 \\
\hline 2. & 20 & 4.71 & 1.402 & 411727 \\
\hline 3. & 30 & 4.721 & 1.365 & 619099 \\
\hline 4. & 40 & 4.75 & 1.324 & 817548 \\
\hline 5. & 50 & 4.768 & 1.291 & 1030441 \\
\hline \multicolumn{2}{|c|}{ Mean } & 4.7218 & 1.372 & 3109266 \\
\hline \multicolumn{2}{|c|}{$\%$ RSD } & 0.87889 & 5.28739 & 10.20345 \\
\hline \multicolumn{2}{|r|}{ Limits } & & $<2$ & $>2000$ \\
\hline
\end{tabular}

\section{Analysis of marketed formulation}

The assay of Dothiepin in marketed formulation was evaluated by comparing the area of the standard Dothiepin with the tablet sample. The percent assay was found to be 99.06 which is found to be in limits and the results were tabulated in Table 9.

Table 9: Assay

\begin{tabular}{|l|l|l|l|l|}
\hline S.no & Drug & Labelled claim $(\mathbf{m g})$ & Mean \pm SD & \%RSD \\
\hline 1. & Dothiepin hydrochloride & 25 & $99.06+0.8016$ & 0.809 \\
\hline
\end{tabular}

Table 10 Summary of validation parameters

\begin{tabular}{|l|l|l|}
\hline S.no & Parameter & Dothiepin \\
\hline 1. & Linearity(R2) & 0.999 \\
\hline 2. & Accuracy(Mean) & $99.996 \%$ \\
\hline 3. & Precision(\%RSD) & 0.0051 \\
\hline 4. & Robustness & Within the acceptance criteria \\
\hline 5. & Assay & $99.06 \%$ \\
\hline 6. & Theoritical plates \%RSD Tailing factor & 3109266 \\
& System suitability & 1.372 \\
& \multicolumn{1}{|c|}{0.8788} \\
\hline 7. & LOD and LOQ & 0.059221 and $0.179456 \mu \mathrm{g} / \mathrm{ml}$. \\
\hline 8. & Specificity & No interferences are observed due to blank \\
& & and placebo. \\
\hline
\end{tabular}




\section{Conclusion}

A novel RP-HPLC method has been developed which is LC-MS compatible and validated as per ICH Q2(R1) guidelines for the parameters like linearity, accuracy, precision, robustness, specificity and assay. No interferences are observed from any other excipients of dosage form and the developed method has been successfully applied for the routine quality control analysis.

\section{Acknowledgement}

The authors are thankful to management and principal of K.V.S.R. Siddhartha college of pharmaceutical sciences, Vijayawada, India and sincere thanks to lifeline formulations for providing the drug sample to carry out the research work.

References

[1]. The Merck index An encyclopedia of chemicals, drugs and biologicals- $12^{\text {th }}$ edition, The Merck research laboratories white house station, NJp.3485;1996

[2]. The Indian Pharmacopoeia , Indian pharmacopoeia commission, Ghaziabad, $10^{\text {th }}$ edition, volume II p.1250,1251, 2010.

[3]. Martindale- The complete drug reference $33^{\text {rd }}$ edition; The Royal pharmaceutical society, London p.283, 1993.

[4]. Xiang chen,Ben-Mei chen, shao-Gang liu,Fu-Liang Denga, ping zhou, Determination of Dothiepin in human plasma by LC-ESIMS and its application to bioequivalence studies, Chromatographia,68, 2008, p.941-947.

[5]. Nour Abdel-ghani, Rasha el nashar, AABioumy, Flow injection potentiometric determination of Dothiepin hydrochloride, Anal.Lett,37(15), 2004, p.3237-3254.

[6]. FatmaM.Abdel-Gawad, Ahmed G.Helmy and emanF.Mohamed, potentiometric method for the determination of Lamivudine and Dothiepin hydrochloride in pharmaceutical preparations, Anal.Bioanal.electrochem, 5(2), 2013, p.222-235.

[7]. Nour T. Abdel ghani, Rasha Mel-Nashar, Abeer A Bioumy, conductimetric Determination of the antidepressants AmitryptilineDothiepin hydrochloride $\mathrm{Hcl}$ and Tranylcypromine hemisulphate in their pharmaceutical dosage forms, FABAD J.pharm sciences, 2004.

[8]. O.Abd el-aziz, M.Faruk, A.E.E.I-Gindy,E.A. Abdullah, Validated stability indicating methods for the determination of Dothiepin hydrochloride, Analytical chemistry, an Indian journal,10 (5),2011, p,283-293.

[9]. L.ShivakumarReaddy, DR.S.L.N.Prasad Reddy, G.Srinivas Reddy, Validated stability indicating liquid chromatographic method for simultaneous estimation of Dosulepin and methylcobalamin in combined pharmaceutical dosage form, An International journal of pure and applied chemistry, Vol 6(6)

[10]. Sameer A.M. Abdulrahman, K.Basavaiah, M.X.Cijo, K.B.Vinay, Validation of UV spectroscopic methods for the determination of Dothiepin hydrochloride in pharmaceutical dosage form and stress degradation studies, Journal of Applied Spectroscopy, 79(5), 2012, p.780-787.

[11]. M.L.Walash, F.Belal, N.EI-Enany andH.Elmansi Spectrophotometric and Spectroflourimetric methods for the determination of Dothiepin hydrochloride in its pure and dosage form using Eosin, International journal of Biomedical sciences,6(4), 2010, p.327334.

[12]. Aruna P, A.Ajitha, V.Umamaheswarrao, Analytical method development and validation of simultaneous estimation of dosulepin and methylcobalamin in tablet dosage form by RP-HPLC, International journal of pharmacy,4(3), 2014, p.267-274.

[13]. Usharanigundala, chandrashekarBonagiri, Devannanayakanti, Simultaneous estimation of dosulepin and methylcobalamin in bulk and pharmaceutical formulation by reverse high performance liquid chromatography(RP-HPLC), IOSR Journal of pharmacy and biological sciences, 9(3), 2014, p.55-59.

[14]. Dhara .Desai, Dimal A Shah, FalgunAmehta, Usmanganik.chhalotiya and Kashyap k Bhatt, Liquid chromatographic estimation of dosulepin hydrochloride and methylcobalamin in pharmaceutical formulation, Journal of pharmaceutics and nanotechnology, p.2347-7849.

[15]. Anita Ayre, Komalghude, MayuriNemade, Priya mane, paraaggide,Development and validation of RP-HPLC method for the determination of Dothiepin hydrochloride in bulk and pharmaceutical dosage form, International journal of chemical and pharmaceutical analysis 1(1), 2013, p.9-13.

[16]. Rambabuchintala, V.Venkatrao sure, Umamaheswar korrapati, Development and validation of a RP-HPLC method for the determination of dosulepin in pharmaceutical formulation, American journal of pharmatech research, 3(2), 2013.

[17]. ICH Q2A, Text on validation of Analytical procedures, International conference on Harmonization, Geneva, October 1994, 1-5.

[18]. ICH Q2B Validation of Analytical procedures; methodology, International conference on Harmonization, Geneva, November 1996, $1-8$. 